\title{
Towards uterine inversion: Illustration of a gradual process through three cases of submucous myoma
}

\author{
Kesang D Bista, Ashma Rana, Geeta Gurung, Neelam Pradhan, Archana Amatya
}

\begin{abstract}
:
How the largest of the large (> $10 \times 8 \mathrm{cms}$ ) sub mucous myoma arising from the fundus uteri successively promotes the occurrence of non puerperal uterine inversion over the years as depicted through 3 different illustrations imitating a gradual process; first by forming an indentation in the uterine fundus then progressively causing more dimpling in the verge of uterine inversion until finally giving rise to a full blown picture of complete uterine inversion where the uterine fundus is driven beyond the level of introitus with the consequences of prolapsed incarcerated myoma in a post menopausal woman.

A total abdominal hysterectomy and bilateral salpingoophorectomy were performed on all of these 3 women 2 perimenopausal and a postmenopausal; the latter was first facilitated by vaginal myomectomy further supplemented by division of the inversion ring posteriorly as described by Haultain.
\end{abstract}

Key words: Non puerperal uterine inversion, submucous fundal myoma, vaginal myomectomy.

\section{Introduction}

A fundal submucous myoma has a capacity to cause uterine inversion provided it is large and heavy so that it gravitationally pulls the uterine fundus along with it to appear outside the cervix and into the vagina; the end result being a prolapsed myoma lying outside the introitus and consequently with the inverted uterus. This process may take years making uterine inversion due to myoma a rare possibility, simply because sub mucous myoma are mostly symptoms producing where women often seek help for various reasons such as, menorrhagia or vaginal discharge before the occurrence of uterine inversion.

We would like to illustrate the anecdotal accounts of uterine inversion related with 3 different case reports.

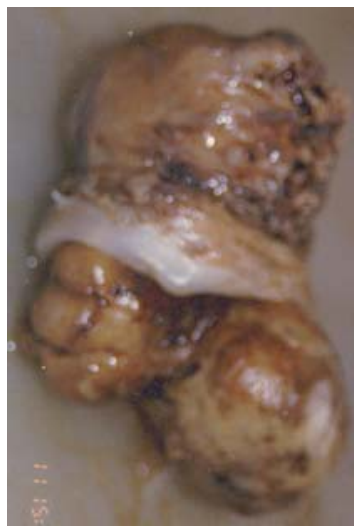

Fig 1a. Prolapsed bilobed myoma on the verge of inverting the uterus shown with double indentations

\section{Case I}

About 5 years back, a woman of reproductive agewho had completed her family came to us with menorrhagia, vaginal discharge and pelvic examination detected a huge polyp measuring 10x8 cms. After preoperative work, which was normal, she was subjected to total abdominal hysterectomy and bilateral salpingo-ophorectomy (TAHBSO). As the abdomen was opened, there was an enlarged uterine size of 8-10 weeks of pregnancy and two indentations were seen in the uterine fundus. Examination of the specimen showed that the bilobed myoma roughly measuring $10 \times 8 \mathrm{cms}$ together was larger than the uterus (fig 1a $\&$ b) and the woman had a speedy postoperative recovery.

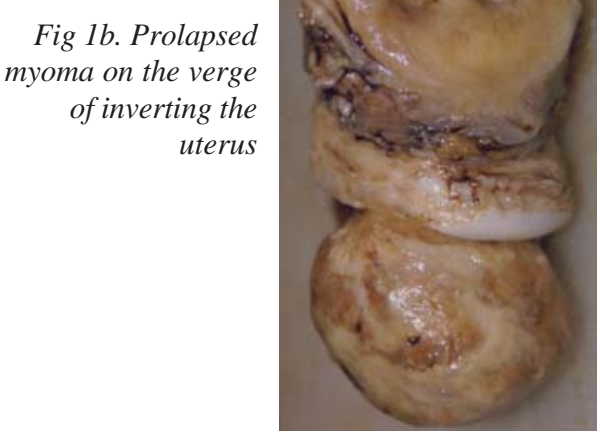

\section{Correspondence}

Prof Ashma Rana, MD FICS. Former Head of Dept of Obs/Gyn TUTH and

Ex member of Academic council of Tribhuvan University, Nepal.

E-mail prof.drranaa@gmail.com, Phone: 9771-5523474 (Res) 9771-5545466(Res), Fax: 977-1-4260940. 


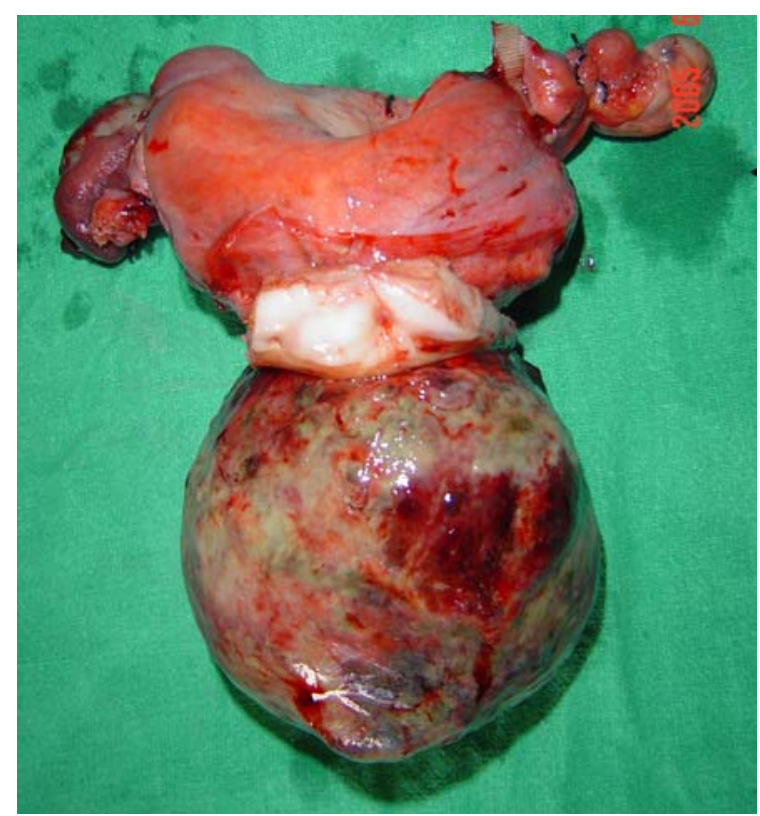

Fig 2a. Sub mucous myoma attempting to cause inversion seen here is double indentations in the fundus

\section{Case 2.}

A year back, a 40 years old lady, $\mathrm{P}_{6} \mathrm{~A}_{2}$ with the history of irregular vaginal bleeding that changed into continuous one over the 9 months period walked inside our out patient clinic accompanied by her son, 18 years of age, with a smelly odor that spread the whole of the corridor. She was quickly taken for examination to avoid the offensive vaginal odor that was difficult to bear when a speculum examination denoted a blackish necrotic growth filling the entire vagina in the presence of putrid and malodorous vaginal discharge, which was collected for culture and sensitivity. A finger could be run all around the cervical Os at bimanual vaginal examination with the appreciation of uniformly enlarged polypoidal growth measuring $10 \mathrm{X} 12 \mathrm{cms}$ projecting into the vagina. Although afebrile she was started on intravenous antibiotics cefotaxime $1 \mathrm{gm} 12$ hourly along with IV $500 \mathrm{mg}$ metronidazole 8 hourly. Oral antiinflammatory medications were also given on 6 hourly basis and betadine vaginal cleansing was done twice a day, betadine vaginal pessary being inserted at bed time. Within the next 4 days, vaginal discharge became less putrid and by the end of a week vaginal discharge happened to look slightly pinkish. She was prepared

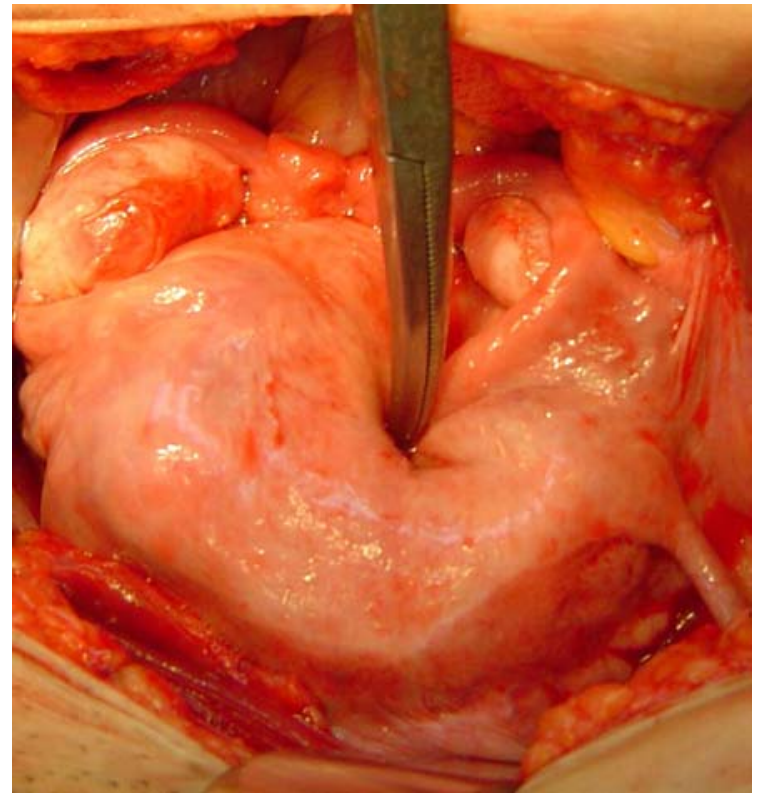

Fig 2b. Sub mucous myoma; note that the tubes are drawn in to the inversion ring

for TAHBSO even though the sonology was inconclusive about the origin of the mass doubt laid more on cervical myoma. Whereas at laparotomy, one of the fallopian tubes was found to be drawn inside an inverted depression in the uterine fundus, probably an inversion ring which was on the process of formation (fig 2a). A routine hysterectomy was done delivering the uterus from below. Gross examination of the specimen showed that the myoma was almost in the verge of causing uterine inversion. Slight reduction in the size of the fibroid polyp was also noticed, which might have been from the subsidence of inflammatory oedema (fig 2 b). She did well postoperatively and antibiotics were stopped after 72 hours of operation and she was discharged on her 6th postoperative day.

\section{Case 3:}

Almost 9 years ago, a postmenopausal lady in her late sixties who exactly did not remember anything contributory to a mass protruding into the vagina for almost a year's history attended Prasutigriha Hospital. There was history of vaginal discharge and difficulty in walking due to the mass. 
Examination revealed a myoma $12 \times 14 \mathrm{cms}$ that had prolapsed out of the vagina (3a) without any associated uterovaginal prolapse or any incarceration of the uterus. No additional mass could be palpable anywhere in the abdomen or suprapubically from pelvic examination, which was difficult.

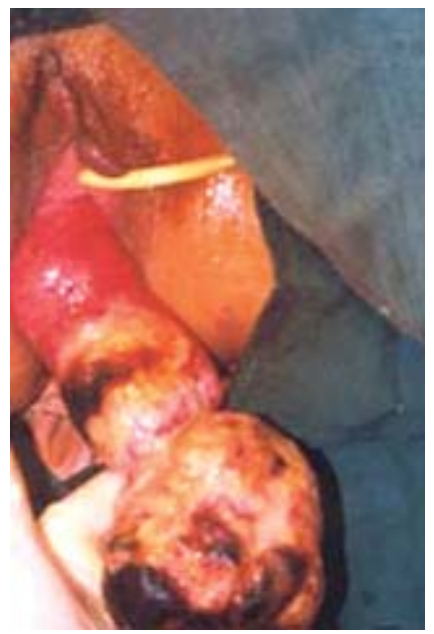

Fig 3a. Huge

Prolapsed

myoma

Under general anesthesia, vaginal myomectomy was done removing only the myoma followed by laparotomy which comprised of visualization of the inversion ring abdominally (fig $3 \mathrm{~b}$ ), followed by Haultain's way of posterior division of this ring reverting the uterine fundus; thereby completing the removal of uterus and ovary entirely as in a usual routine approach.

The patient had a speedy recovery.

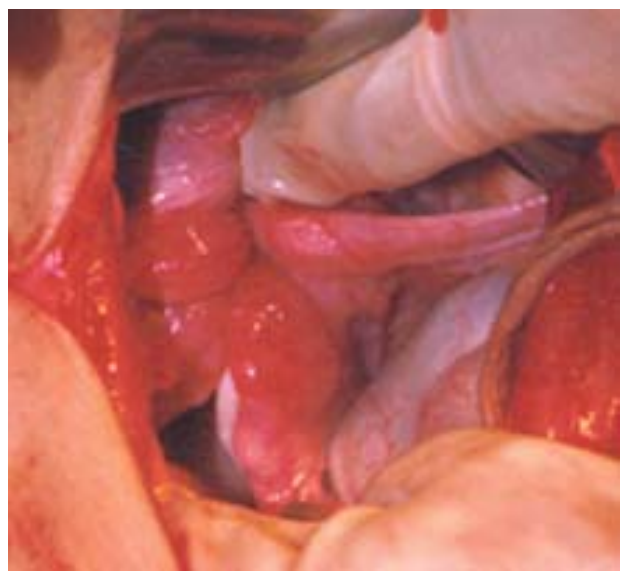

Fig $3 b$ Laparotomy display of tubes and ovaries drawn inside the inversion ring

\section{Discussion}

Non puerperal uterine inversion from submucous myoma running probably over a substantial period has been described with the initiation of a gradual process of inversion which when timely combated before the myoma could provoke full blown picture of uterine inversion in the first 2 cases explain why there is lesser prevalence of uterine inversion. Whereas extremely neglected submucous as in the last case could bring about non puerperal uterine inversion, a rare entity.

The varied presentations of myoma is dictated from its location and in this context one must realize how differently a sub mucous myoma can behave in abortive phases producing strange body vaginal sensation to the extent of being incarcerated procidentia once after extrusion, being incorporated with severe vaginal bleeding and pelvic pain at times. ${ }^{1,2}$ However the association of sub mucous myoma with uterine inversion appears to be very small with few reported cases. $^{3-6}$

This may be because of the slower growth rate of sub mucous myoma, a time consuming process which manifest only in some of neglected cases like that of ours in form of chronic uterine inversion due to prolapsed submucous myoma as most of them are handled before uterine inversion ensues. It's to be learned that an unidentified myoma in sub mucous uterine fundal location will grow to a compellingly larger size and volume in such a way to be able to produce uterine inversion in days to come although some atypical myoma are also seen to produce uterine inversion. ${ }^{7-10}$

\section{Conclusions}

From the above observations we have realized that a sub mucous myoma, fundal in origin if left untreated for a long time one day will ultimately produce uterine inversion once the size and volume become larger and heavier.

\section{Acknowledgement}

We would like to extend our heartfelt thanks to Prof. DS Malla, Prof. Kanti Giri, Prof. Saraswoti Padhye, teaching unit of Maternity Hospital, Prasuti Griha, Thapathali. 


\section{References}

1. G. Kadir, S. Selen, T. Yildiz A, N.Murat, K. Fahrettin. The management of an unusually sited isthmicocervical leiomyoma and a huge prolapsed pedunculated submucous leiomyoma. Gynecological Surgery. Springer-Verlag GmbH Issue: 2, Number 1. DOI: 10.1007/s10397-005-0086-8.

2. Suneja A, Taneja A, Guleria K, Yadav P, Agarwal $\mathrm{N}$. Incarcerated procidentia due to cervical fibroid: an unusual presentation. Aust N Z J Obstet Gynaecol. 2003 Jun; 43(3):252-4.

3. Barick RD, Shambharkar C. Fundal leiomyoma presenting as acute on chronic uterine inversion.Shivkumar PV, J Obstet Gynaecol.2005; 25 (8): 832-3.

4. Kopal S, Seckin NC, Turhan NO. Acute uterine inversion due to a growing submucous myoma in an elderly woman: case report. Eur J Obstet Gynecol Reprod Biol. 2001; 99(1): 118-20.
5. Henderson PR. A large submucous fibroid polyp causing inversion of the uterus. Aust N Z J Obstet Gynaecol.1980; 20(4): 251-4.

6. Mayadeo NM, Tank PD. Non-puerperal incomplete lateral uterine inversion with submucous leiomyoma: a case report. Obstet Gynaecol Res. 2003; 29(4): 243-5.

7. Adaji SE, Randawa AJ, Shittu OS. Idiopathic chronic uterine inversion in a nulligravida. Int $\mathrm{J}$ Gynaecol Obstet. 2005; 89(1):61-2.

8. Skinner GN, Louden KA. Non-puerperal uterine inversion associated with an atypical leiomyoma. Aust N Z J Obstet Gynaecol. 2001 Feb; 41(1): 100-1.

9. Rosales Aujang E, Gonzalez Romo R. Inversion uterine non-puerperal. A report of a case. Ginecol Obstet Mex. 2005; 73(6): 328-31.

10. Lai FM, Tseng P, Yeo SH, Tsakok FH. Nonpuerperal uterine inversion- a case report. Singapore Med J. 1993; 34(5): 466-8. 